\title{
魚類肝臟中の發徽防止成分(豫報) \%
}

On the unknown principle in fish liver which prevents the growth of moulds. (prelimirary report)

\author{
山田紀作・篠山茂行 K. YAMADA, and S. SASAYAMA
}

(水造試羷堨)

The following facts were found that the growth of mycelium and spore showed different phase, being compared with control, when the boiled extract of the bonito liver was added to the culture medium, and that the growth of mould was prevented when the extracted soution was only used as the culture medium.

\section{緒言 言}

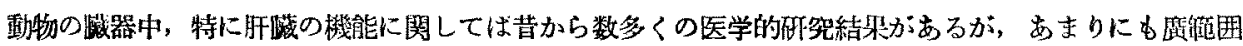

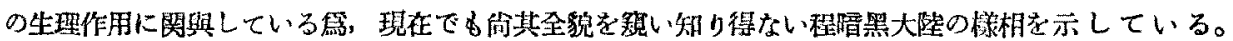

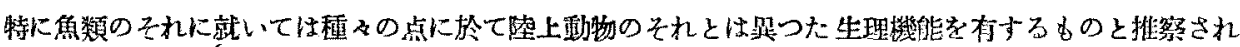

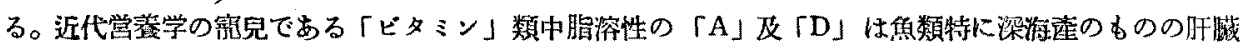

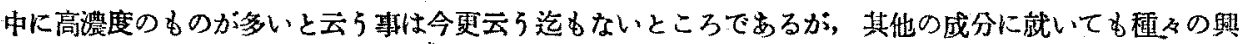

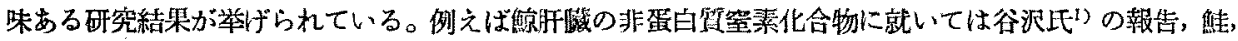

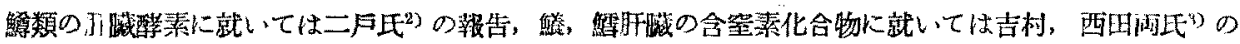

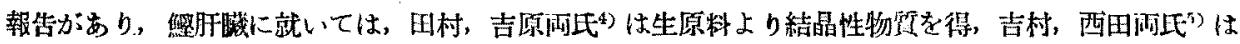

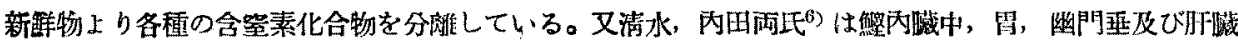

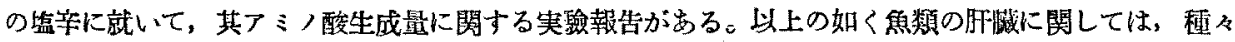

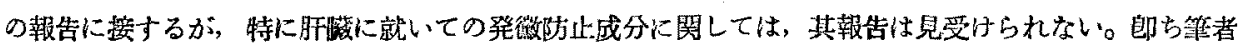

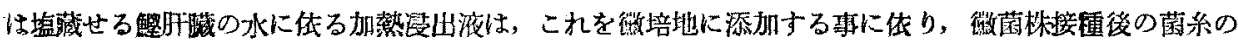

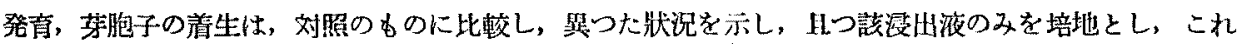

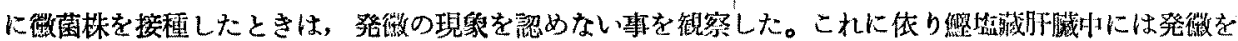
防止或は抑制する成分が含有せられているのではなかららかと推察し，之れと就いて行つた基整的笑驗 結果堂報告する。

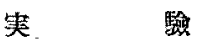

奏 驗 I.

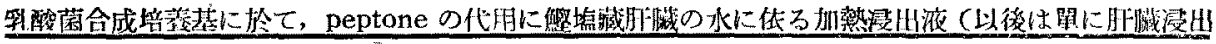

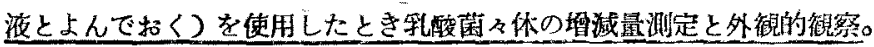

○肝藏漫出液調掣法

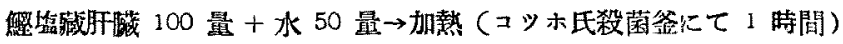

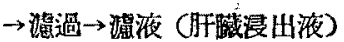

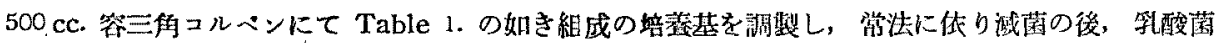

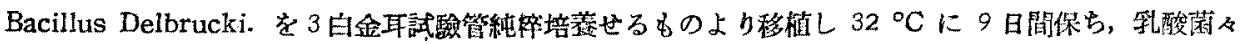

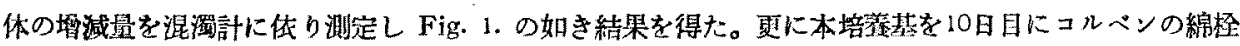
を取り，30 分間空氣中に放血の後再び綿栓を施し. $32^{\circ} \mathrm{C}$ に保ち微の発生の有無を観察した。その結果 
Table. 2 の如L。

Table 1. Composition of Lactic Acid Bacteria culture medium.

\begin{tabular}{c|c|c|c|c|c}
\hline & A & B & C & D & E \\
\hline $\mathrm{KH}_{2} \mathrm{PO}_{4}$ & $0.1 \mathrm{~g}$ & $0.1 \mathrm{~g}$. & $0.1 \mathrm{~g}$. & $0.1 \mathrm{g.}$ & - \\
$\mathrm{MgSO}_{4}$ & 0.1 & 0.1 & 0.1 & 0.1 & - \\
$\mathrm{NaCl}$ & 0.2 & - & - & - & - \\
Glucose & 15 & 15 & 15 & 15 & - \\
peptone & 1.0 & - & - & - & - \\
extract of liver & - & $10 \mathrm{cc}$. & $25 \mathrm{cc}$. & $50 \mathrm{cc}$ & $200 \mathrm{cc}$. \\
water & $200 \mathrm{cc}$. & 200 & 200 & 200 & - \\
salt & $0.1 \%$ & $0.95 \%$ & $2.2 \%$ & $4.0 \%$ & $20 \%$ \\
\hline
\end{tabular}

Table 2. The growth of mould on the culture medium.

\begin{tabular}{|c|c|c|c|c|c|c|c|c|}
\hline culture medium & 1 & 2 & 3 & 4 & 5 & 6 & 7 & 9 \\
\hline A & $\begin{array}{c}\text { No } \\
\text { variation }\end{array}$ & $\begin{array}{l}\text { White } \\
\text { mycelium } \\
\text { was } \\
\text { slightly } \\
\text { found }\end{array}$ & $\begin{array}{c}\text { White } \\
\text { mycelium } \\
\text { was } \\
\text { found } \\
\text { around } \\
\text { the flask }\end{array}$ & $\begin{array}{c}\text { Liquid } \\
\text { surface } \\
\text { was } \\
\text { coverd } \\
\text { by white } \\
\text { mycelium }\end{array}$ & $\begin{array}{c}\text { Brown } \\
\text { spore } \\
\text { was found }\end{array}$ & $\begin{array}{l}\text { Liquid } \\
\text { surface } \\
\text { was } \\
\text { coverd } \\
\text { by spore }\end{array}$ & $\begin{array}{l}\text { same } \\
\text { as left }\end{array}$ & 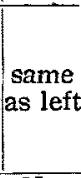 \\
\hline B & $\begin{array}{c}\text { No } \\
\text { variation }\end{array}$ & $\begin{array}{c}\text { No } \\
\text { variation }\end{array}$ & $\begin{array}{c}\text { No } \\
\text { variation }\end{array}$ & $\begin{array}{c}\text { No } \\
\text { variation }\end{array}$ & $\begin{array}{c}\text { No } \\
\text { variation }\end{array}$ & $\begin{array}{c}\text { No } \\
\text { variation }\end{array}$ & \begin{tabular}{|l|} 
No \\
varia- \\
tion' \\
\end{tabular} & $\begin{array}{l}\text { No } \\
\text { varia- } \\
\text { tion }\end{array}$ \\
\hline C & $\begin{array}{c}\text { No } \\
\text { variation }\end{array}$ & $\begin{array}{c}\text { No } \\
\text { variation }\end{array}$ & $\begin{array}{c}\text { No } \\
\text { variation }\end{array}$ & $\begin{array}{c}\text { No } \\
\text { variation }\end{array}$ & $\begin{array}{c}\text { No } \\
\text { variation }\end{array}$ & $\begin{array}{c}\text { No } \\
\text { variation }\end{array}$ & \begin{tabular}{|l|} 
No \\
varia- \\
tion
\end{tabular} & $\begin{array}{l}\text { No } \\
\text { varia- } \\
\text { tion }\end{array}$ \\
\hline $\mathrm{D}$ & $\begin{array}{c}\text { No } \\
\text { variation }\end{array}$ & $\begin{array}{c}\text { No } \\
\text { variation }\end{array}$ & $\begin{array}{c}\text { No } \\
\text { variation }\end{array}$ & $\begin{array}{c}\text { No } \\
\text { variation }\end{array}$ & $\begin{array}{l}\text { No } \\
\text { variation }\end{array}$ & No & \begin{tabular}{|c|} 
No \\
varia- \\
tion
\end{tabular} & $\begin{array}{c}\text { No } \\
\text { varia- } \\
\text { tion }\end{array}$ \\
\hline $\mathrm{E}$ & $\begin{array}{c}\text { No } \\
\text { variation }\end{array}$ & $\begin{array}{c}\text { No } \\
\text { variation }\end{array}$ & $\begin{array}{l}\text { No } \\
\text { variation }\end{array}$ & $\begin{array}{c}\text { No } \\
\text { variation }\end{array}$ & $\begin{array}{l}\text { No } \\
\text { variation }\end{array}$ & $\stackrel{\text { No }}{\text { yariation }}$ & $\begin{array}{l}\text { No } \\
\text { varia- } \\
\text { tion }\end{array}$ & $\begin{array}{l}\text { No } \\
\text { varia- } \\
\text { tion }\end{array}$ \\
\hline
\end{tabular}

\section{考察}

1，乳酸菌培塊基の組成中 peptone の代用に肝藏浸出液を使用したところ，乳酸菌々体の㙁減量は

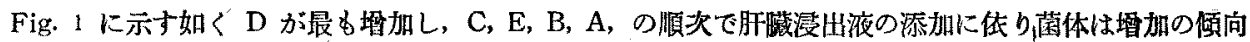
を示し，peptoneの代用として良好であるばかりでなく，菌体增殖にも好遮のものであると考えられる。

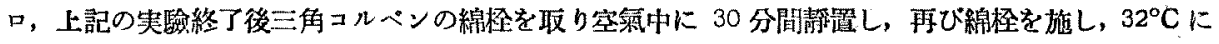
保ちたるところ, Table. 2 に示才如く A には微の発生を認めたが, 他の B，C，D，Eにはこれを㑇め

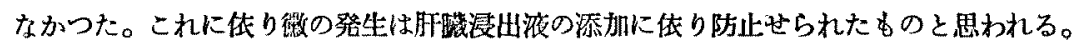

奏臨 11 .

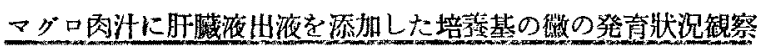

○マダロ肉汁調艎法 


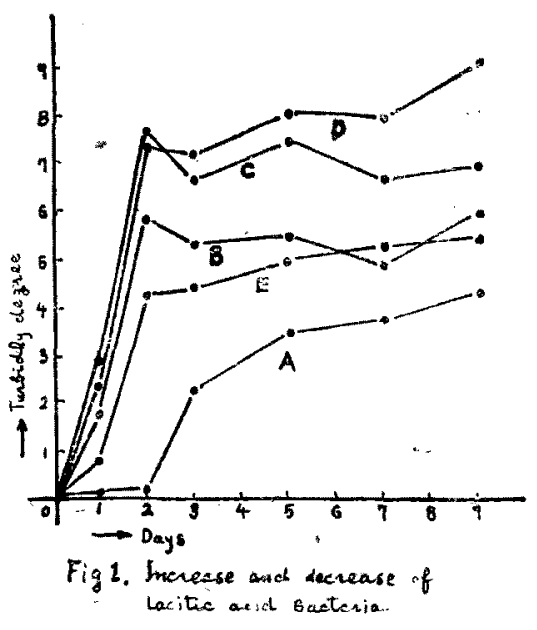

Table 3. Composition of culture medium.

\begin{tabular}{l|l}
\hline & kind of culture medium \\
\hline$\left(A_{1}\right)$ & extract of tuna meat $100 \mathrm{cc}$. \\
\hline$\left(B_{1}\right)$ & $\begin{array}{l}\text { extract of tuna meat } 100 \mathrm{cc} . \\
+ \text { extract of fiver } 10 \mathrm{cc} .\end{array}$ \\
\hline$\left(C_{1}\right)$ & $\begin{array}{l}\text { extract of tuna meat } 100 \mathrm{cc} . \\
+ \text { extract of liver } 25{ }^{\circ} \mathrm{G} .\end{array}$ \\
\hline$\left(D_{1}\right)$ & extract of liver $100 \mathrm{cc}$. \\
\hline
\end{tabular}

マグロ鮮肉 $\rightarrow$ 肉抬（肉量 250 量） $\rightarrow$ 水

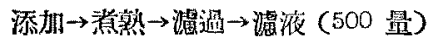

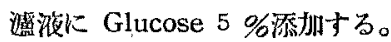

○肝瞵浸出液調製法

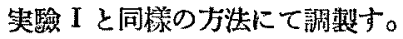

Table. 3 K示しな如き培墓基 $\left(\mathrm{A}_{1}\right),\left(\mathrm{B}_{1}\right),\left(\mathrm{C}_{1}\right)$, $\left(D_{1}\right)$ の四種を $300 \mathrm{cc}$. 篗三解コルペンにて常法に從い

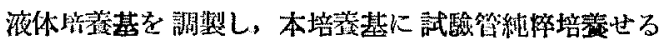
Asp-oryzae, soya $の$ 菌林を 2 日金耳移植し, $32^{\circ} \mathrm{C} に$ 5 日間保ちその狀况を镀察した。その結果 Table. 4 の 如し。

考察

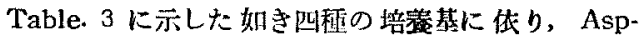

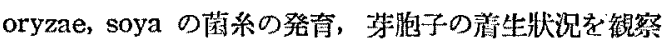
したところ, $32{ }^{\circ} \mathrm{C}, 5$ 日日で Table. 4 に示した如く

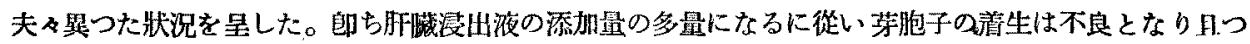

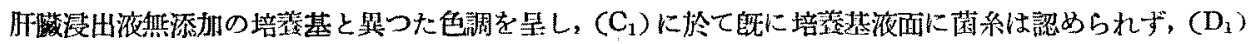

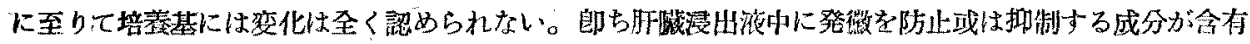
せられているものと思われる。

実 䮯 III.

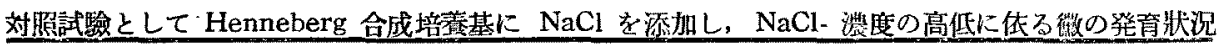
榷祭

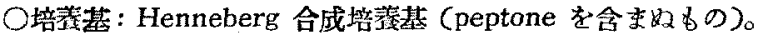

○培基食壏濃：0\%，5\%，10\%，15\%，20\%，25\%，30\%，50\%の八灀。

O菌穤 : Asp-Katuobusi, Asp-melleus, Asp-Pseudoflavus, Asp-oryzae soya の四種。

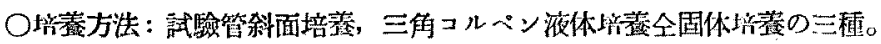

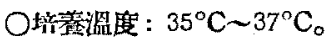

○培恶期間：5 日間。

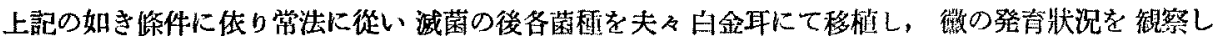
た。その結果 Table. 5, Table. 6 の如し。 
Table 5. The growth of mould by sloping culture of test tub (on the fifthe clay)

\begin{tabular}{c|r|r|r}
\hline mould & o. 5. $10 \%$ & $15 \%$ & $20 \sim 50 \%$ \\
\hline Asp-Katuobusi & Growing condition & The white mycelium & The growth of mycelium \\
Asp-melleus & was regular & $\begin{array}{c}\text { Growing condition } \\
\text { was bad. } \\
\text { The dissolution of } \\
\text { agaragar was found. }\end{array}$ & $\begin{array}{c}\text { Agaragar being } \\
\text { dissolved. } \\
\text { The sloping form } \\
\text { was not kept. }\end{array}$ \\
\hline
\end{tabular}

Table 6. The growth of mould (Asp-oryzae-soya)

in Erlemneyer flasks (on the fifthe day).

\begin{tabular}{|c|c|c|c|c|}
\hline $\begin{array}{l}\text { kind of } \\
\text { culture medium }\end{array}$ & $0.5 \%$ & $10 \%$ & $15 \%$ & $20 \sim 50 \%$ \\
\hline liquid culture & $\begin{array}{l}\text { Light green spore } \\
\text { was found. } \\
\text { Growing condition } \\
\text { was regular }\end{array}$ & same as left. & $\begin{array}{c}\text { The white } \\
\text { mycelium with } \\
\text { wrinkle was partly } \\
\text { formed. The spore } \\
\text { was not found. }\end{array}$ & No variation \\
\hline $\begin{array}{l}\text { solid culture } \\
\text { (agaragar } 2 \%)\end{array}$ & $\begin{array}{c}\text { Dark green spors } \\
\text { were found. } \\
\text { Growing condition } \\
\text { was regular. }\end{array}$ & $\begin{array}{l}\text { The green spores } \\
\text { were partly } \\
\text { fromed. }\end{array}$ & $\begin{array}{l}\text { The white } \\
\text { mycelium was } \\
\text { partly found. } \\
\text { The spore was } \\
\text { not formed. }\end{array}$ & $\begin{array}{l}\text { The mycelium was } \\
\text { not found. The } \\
\text { dissolution of } \\
\text { agaragar was } \\
\text { found. }\end{array}$ \\
\hline
\end{tabular}

\section{考察}

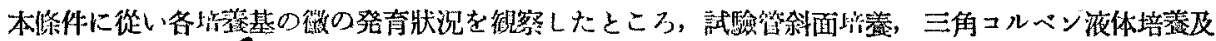

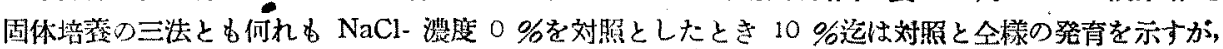

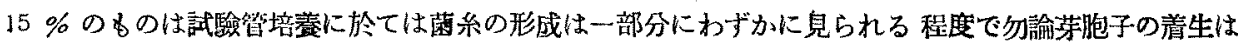

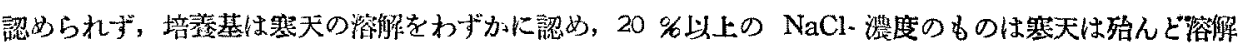

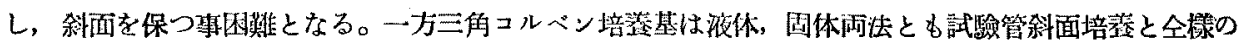

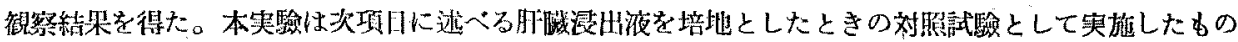
である。

实 嬏 IV.

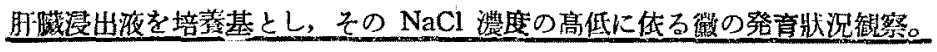

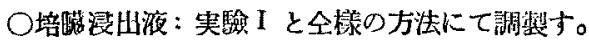

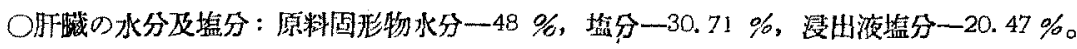

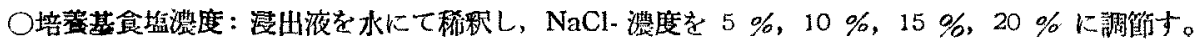

○菌程: Asp-oryzae-soya.

O度出液 $\mathrm{pH}: \mathrm{HCl}$ て 5.4 に調節す。

O培盖溫度: $35^{\circ} \mathrm{C} \sim 37^{\circ} \mathrm{C}$.

○培菱期間：5 日間。 


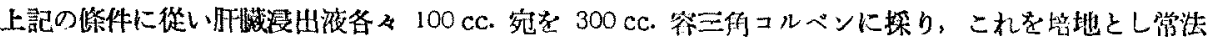

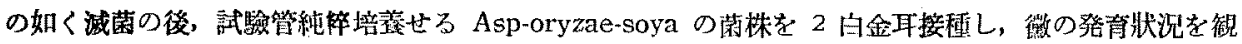
察した。その結果 Table. 7 の如し。

Table 7. The growth of mould in the culture medium with the extract of liver. (on the fifthe day)

\begin{tabular}{c|c|c|c|c}
\hline mould & $5 \%$ & $10 \%$ & $15 \%$ & $20 \%$ \\
\hline Asp-oryzae soya & $\begin{array}{c}\text { The white film with } \\
\text { wrinkle was partly } \\
\text { formed, the formation } \\
\text { of greenish yellow } \\
\text { spores was slightly } \\
\text { found. }\end{array}$ & $\begin{array}{c}\text { The film wastly formed. } \\
\text { pound }\end{array}$ & $\begin{array}{c}\text { mycelium was } \\
\text { not found. }\end{array}$ & No variation. \\
\hline
\end{tabular}

考察

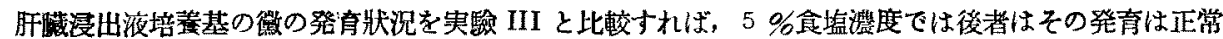
であるが，前者は Table. 7 に示す如く鼠つた菌系，芽胞子の発育を示し，且つ黑うた芽胞子（菌叢） の色を示した。10％ではその状況は更に不良となり，15\%以上では菌系の発生は認められず，何れも

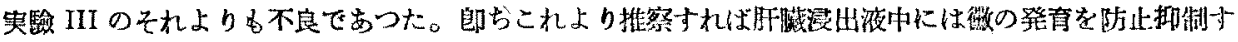
る成分が含有せられているものと思われる。

要

約

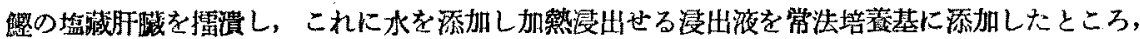

1. 肝瀻浸出液は乳酸菌培㝨基の peptone の代用になりり得る。

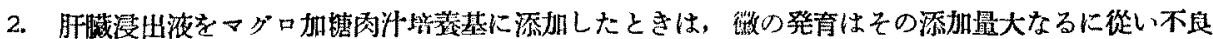

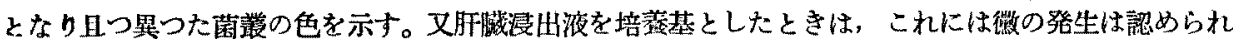
ない。

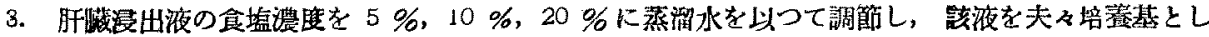

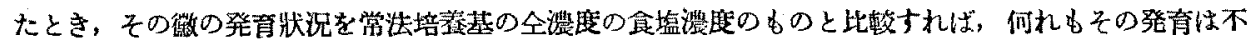
良で且つ巽つた菌系の発生椂相, 菌叢の色を示す。

結語

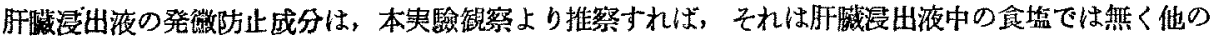

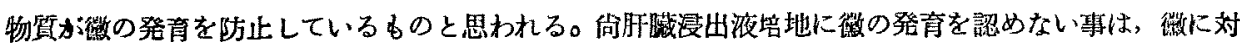
する培地営養源の不足とも考えられるが，是等に就いては今後の代究課題とする。

1. 谷沢, ; J, J, M, B, 2, 43, (1933)

参考交 献

2. 二F; ; 水连研 $31,378,(1936)$

3. 吉村, 西田,; 農化 5,854 , (1929), 農化 6, 927 (1930)

4. 田村, 吉原, ; 水童研, 31,460 (1936)

5. 吉村, 西田, ; 辳化 6, 113 (1930)

6. 清水，內田；水製 $3 ， 223$ （1735）

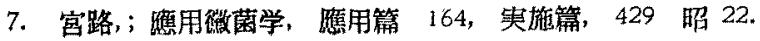

